\title{
Effect of restrictive blood transfusion on postoperative acute kidney injury after total hip replacement arthroplasty: a prospective randomized controlled trial
}

\author{
Hyo Jung Son ${ }^{1}$, Yoon Ji Choi ${ }^{2}$, Ji Yoon Lee ${ }^{2}$, Young Jin Ro ${ }^{3}$ \\ ${ }^{1}$ Department of Anesthesiology and Pain Medicine, National Police Hospital, Seoul, ${ }^{2}$ Department of Anesthesia and Pain Medicine, \\ Korea University Ansan Hospital, Ansan, ${ }^{3}$ Department of Anesthesiology and Pain Medicine, Asan Medical Center, University of Ulsan, \\ Seoul, Korea
}

Received June 24, 2019

Revised July 29, 2019

Accepted August 16, 2019

Corresponding author

Hyo Jung Son

Department of Anesthesiology

and Pain Medicine, National Police

Hospital, Songee-ro 123, Songpa-

gu, Seoul 05715, Korea

Tel: +82-2-3400-1492

Fax: +82-2-3400-1249

E-mail: gidget80@police.go.kr ORCID:

http://orcid.org/0000-0001-7710-7605
Blood transfusion is an important method of fluid management and benefits patients when properly used; however, it involves the risk of side effects such as critical organ damage. This study was designed to evaluate the efficacy and safety of a restrictive transfusion strategy (transfusion threshold of hemoglobin $8 \mathrm{~g} / \mathrm{dL}$ ) compared to a conventional transfusion strategy (transfusion threshold of hemoglobin $10 \mathrm{~g} / \mathrm{dL}$ ) on postoperative AKI among patients undergoing total hip replacement arthroplasty (THRA). Patients undergoing THRA were divided into two groups: restrictive transfusion strategy $(n=72)$ and conventional transfusion strategy $(n=72)$. Stroke volume variation was performed to maintain methods, complications, and preoperative and postoperative laboratory tests. They were categorized according to changes in plasma creatinine $(\mathrm{Cr})$ concentration within 48 hours after THRA using Acute Kidney Injury Network criteria. Acute kidney injury (AKI) occurred in three patients (4.2\%) in the restrictive transfusion strategy group and two patients $(2.8 \%)$ in the conventional transfusion strategy group $(p=0.99)$. The mean serum $\mathrm{Cr}$ levels 48 hours after surgery were $0.76 \pm 0.36$ and $0.66 \pm 0.20 \mathrm{mg} / \mathrm{dL}$ in the restrictive transfusion strategy group and the conventional transfusion strategy group, respectively $(\mathrm{p}=0.30)$. Perioperative restrictive transfusion or conventional transfusion in patients undergoing elective THRA is not related to AKI when maintaining proper volume status during surgery.

Keywords: Acute kidney injury; Anemia; Complication; Total hip replacement arthroplasty; Transfusion

\section{INTRODUCTION}

Hemoglobin $(\mathrm{Hb})$ level of $10 \mathrm{~g} / \mathrm{dL}$ has been widely used as a standard guideline for allogeneic red blood cell (RBC) transfusion. However, recent evidence reveals that a strategy of limited transfusion is more effective than conventional transfusion [1]. Restrictive transfusion strategy that maintains hemoglobin $8 \mathrm{~g} / \mathrm{dL}$ can reduce the risk of $\mathrm{RBC}$ transfusion and have not been found to cause higher rates of adverse events, such as myocardial infarction, acute renal insufficiency, pneumonia, thromboembolism, and stroke than conventional transfusion therapy. Moreover, the use of smaller amounts of allogeneic RBCs may reduce the risk of mortality and morbidity. Indeed, most of the recent RBC transfusion guidelines recommend a more cautious and restrictive approach to allogeneic RBC transfusion, even in 
patients who are critically ill or have pre-existing cardiovascular disease [2,3].

Total hip replacement arthroplasty (THRA) can result in substantial blood loss during surgery and often requires RBC transfusion therapy. Besides, increased life expectancy due to the development of medicine has led to an increased number of hip fractures in the elderly and critically ill patients due to an increased probability of falling as well as osteoporotic changes in the bone [4,5].

To reduce postoperative mortality and morbidity in highrisk patients, many efforts such as different blood transfusion strategies have been made to decrease complications after THRA.

Acute renal dysfunction is a serious adverse event in patients who undergo THRA, occurring in 16\% of THRA patients and resulting in acute kidney injury (AKI) [4]. In addition, postoperative AKI can develop into temporary or chronic kidney disease and be related to poor patient outcomes. AKI is also associated with longer inpatient stay, inpatient morbidity, and mortality [4]. Early detection and proper treatment can help prevent perioperative AKI; thus, the aim of this study was to evaluate the efficacy and the safety of restrictive transfusion strategy (transfusion threshold of $\mathrm{Hb} 8 \mathrm{~g} / \mathrm{dL}$ ) compared to conventional transfusion strategy (transfusion threshold of $\mathrm{Hb}$ at $10 \mathrm{~g} / \mathrm{dL}$ or higher) on postoperative AKI among patients undergoing THRA.

\section{METHODS}

After this study was approved by our Institutional Ethics Committee (2013-1106), written informed consent was obtained from all patients.

A flow diagram of patients throughout the study is presented in Fig. 1. We enrolled 154 American Society of Anesthesiologists (ASA) grade I-II patients between 20-70 years of age who required elective THRA. Exclusion criteria were as follows: use of non-steroidal anti-inflammatory drugs or nephrotoxic drug use, pregnancy, repeated surgery, and history of hepatic, renal, or cardiac disease. Finally, two patients who had repeated surgery and eight patients with cardiac or chronic renal disease were excluded. Patients were randomly allocated with two groups: restrictive transfusion strategy (transfusion threshold of $\mathrm{Hb} 8.0 \mathrm{~g} / \mathrm{dL}$ ) and conventional transfusion strategy (transfusion threshold of $\mathrm{Hb} 10.0$

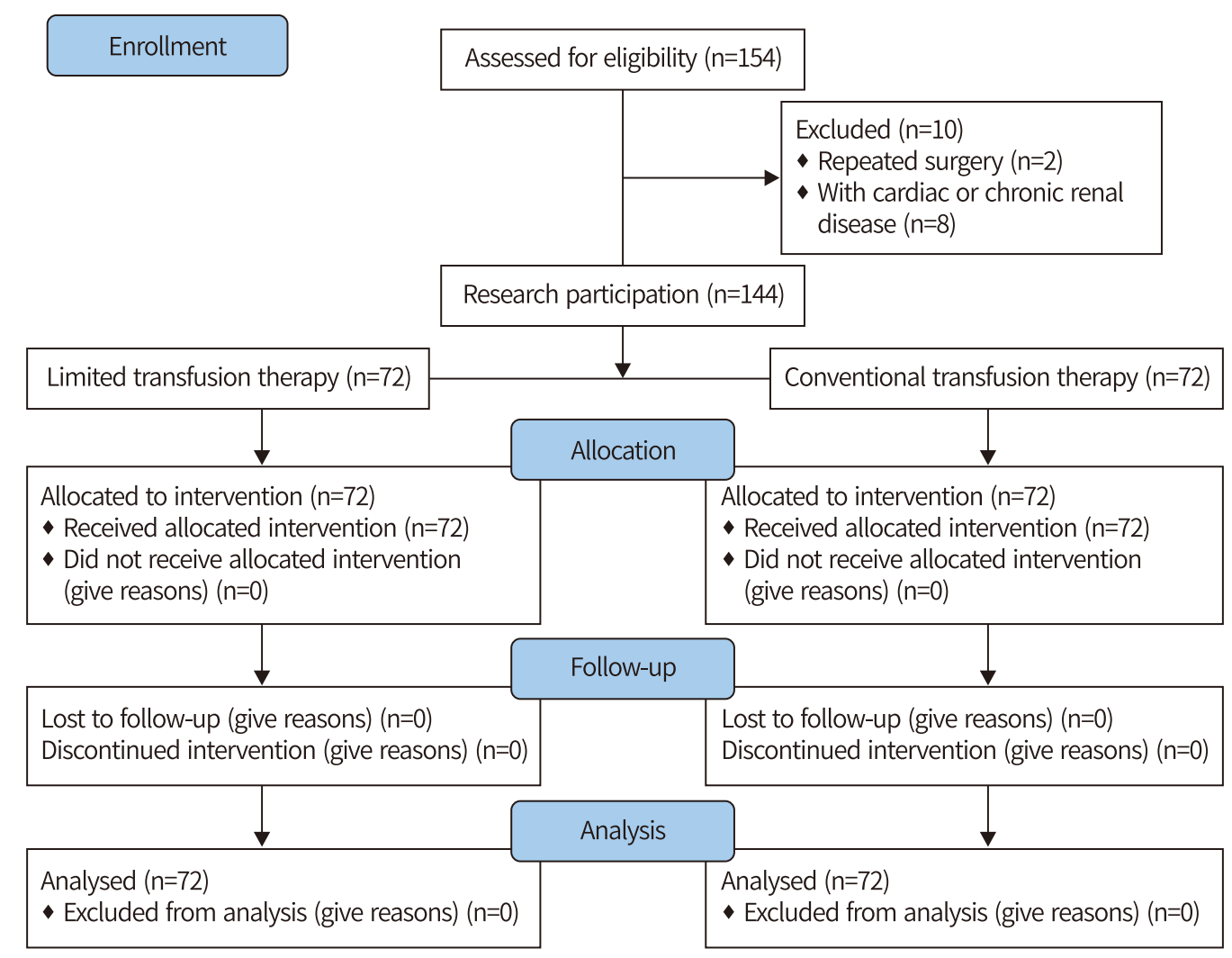

Fig. 1. Flow diagram of patient progression through the study. 
$\mathrm{g} / \mathrm{dL}$ ). For randomization, the generator found at http:// www.randomization.com was used (Number of subjects per block/number of blocks: 12/12, seed number: 1234). Patients' baseline demographics, comorbidities, medications that affect kidney function, and preoperative laboratory findings were collected.

Enrolled patients were anesthetized with general anesthesia. General anesthesia was performed using sevoflurane with $3 \mathrm{~L}$ of fresh gas flow, and rocuronium was administered as a muscle relaxant. Intraoperative monitoring was performed with electrocardiography, invasive surveillance of arterial blood pressure, and pulse oximetry. The FloTrac/ Vigileo (FTV) system version 1.07 (Edwards Lifesciences, Irvine, CA, USA) was applied to monitor stroke volume variation. Both groups maintained less than $13 \%$ of stroke volume variation with the FTV system during surgery. Crystalloids including normal saline or Hartmann's solution were routinely infused to preserve adequate urine output $(>0.5$ $\mathrm{mL} / \mathrm{h}$ ). Intraoperative blood loss was controlled by transfusing packed RBCs to maintain hematocrit above $25 \%$. After the completion of surgery, the patient was extubated in the operating room and transferred to the post-anesthesia care unit. Laboratory data were routinely measured before surgery, after 1 hour of operating, and 48 hours after surgery. Anesthetic time, blood pressure variation during surgery, use of vasopressors, the total dose of postoperative pethidine, volume replacement with fluids and RBCs during surgery, and estimated blood loss were recorded for each patient.

Depending on the Acute Kidney Injury Network (AKIN) criteria, the development of postoperative AKI after THRA was assessed based on changes in serum creatinine $(\mathrm{Cr})$ concentration within 48 hours after surgery. Stage I was defined as an increase of $\geq 0.3 \mathrm{mg} / \mathrm{dL}$ from baseline (normal reference range, $0.7-1.4 \mathrm{mg} / \mathrm{dL}$ at our institution) or an increase of $150-200 \%$ from baseline, stage II as an increase of $200-300 \%$ from baseline, and stage III as an increase of $>300 \%$ from baseline or an increase of $\geq 4.0 \mathrm{mg} / \mathrm{dL}$ from baseline accompanied by an acute increase of $\geq 0.5 \mathrm{mg} / \mathrm{dL}$ from baseline, or the need for renal replacement therapy irrespective of other criteria [6].

\section{Statistical analysis}

To confirm the adequacy of the number of subjects, the G*power software (version 3.1.9.3; Dusseldorf University,
Dusseldorf, Germany) was used [7]. To estimate the sample size for this study, a power analysis revealed that a total of 154 patients were needed in the study groups to determine the incidence of AKI between two groups, at a power of 0.8 , an $\alpha=0.05$, a $5 \%$ drop out rate, and 0.23 of effective size obtained from preliminary results. Continuous variables in this study were expressed as means \pm standard deviations and categorical variables as numbers (percentages). Baseline and intraoperative characteristics and variables for postoperative outcomes were compared using the $\chi^{2}$ test or Fisher's exact test for categorical variables and the $t$-test or the Mann-Whitney rank-sum test for continuous variables. All statistical analyses were conducted using SAS ${ }^{\circledR}$ ver. 9.2 (SAS Institute, Cary, NC, USA). A p-value $<0.05$ was considered to represent a statistically significant difference.

\section{RESULTS}

Demographic data and medical information that were considered to be risk factors for kidney dysfunction and preoperative laboratory results for all patients between January 2014 and August 2016 that were entered into the analysis are listed in Tables 1 and 2. There were no differences in any of the patient characteristics or preoperative laboratory data. Patients' perioperative factors including anesthetic time, estimated blood loss, total fluid intake, and volume of transfusion of RBCs are listed in Table 3. There were no dif-

\begin{tabular}{lccc}
\multicolumn{3}{l}{ Table 1. Patient characteristics } \\
\hline Variable & $\begin{array}{c}\text { Restrictive } \\
\text { transfusion therapy } \\
(\mathrm{n}=72)\end{array}$ & $\begin{array}{c}\text { Conventional } \\
\text { transfusion therapy } \\
(\mathrm{n}=72)\end{array}$ & $\mathrm{p}$ value \\
\hline Gender (M:F) & $26(36.1): 46(63.9)$ & $27(37.5): 45(62.5)$ & 0.50 \\
Age (years) & $55.8 \pm 16.3$ & $51.5 \pm 14.0$ & 0.09 \\
BMl (kg/m $\left.{ }^{2}\right)$ & $23.4 \pm 3.7$ & $24.4 \pm 3.4$ & 0.87 \\
HTN & $41(56.9)$ & $27(37.5)$ & 0.99 \\
DM & $18(25)$ & $15(20.8)$ & 0.97 \\
IHD & $8(11.1)$ & $6(8.3)$ & 0.97 \\
COPD & $20(27.8)$ & $10(13.9)$ & 0.88 \\
With insulin & $3(4.1)$ & $0(0)$ & 0.14 \\
With diuretics & $9(12.5)$ & $5(6.9)$ & 0.85 \\
With ACEi & $1(1.4)$ & $1(1.4)$ & 0.93
\end{tabular}

Data are expressed as the mean \pm SD or number (\%). BMl: body mass index, HTN: hypertension, DM: diabetes mellitus, IHD: ischemic heart disease, COPD: chronic obstructive pulmonary disease, ACEi: angiotensin converting enzyme inhibitor. 
Table 2. Preoperative laboratory data

\begin{tabular}{lccc}
\hline \multicolumn{1}{c}{ Variable } & $\begin{array}{c}\text { Restrictive } \\
\text { transfusion therapy } \\
(\mathrm{n}=72)\end{array}$ & $\begin{array}{c}\text { Conventional } \\
\text { transfusion therapy } \\
(\mathrm{n}=72)\end{array}$ & $\mathrm{p}$ value \\
$\mathrm{Hb}(\mathrm{g} / \mathrm{dL})$ & $12.56 \pm 1.78$ & $13.25 \pm 2.00$ & 0.80 \\
Albumin $(\mathrm{g} / \mathrm{dL})$ & $3.88 \pm 0.53$ & $3.89 \pm 0.52$ & 0.89 \\
$\mathrm{Na}(\mathrm{mEq} / \mathrm{L})$ & $139.82 \pm 3.05$ & $139.90 \pm 2.61$ & 0.94 \\
$\mathrm{~K}(\mathrm{mEq} / \mathrm{L})$ & $4.21 \pm 0.43$ & $4.15 \pm 0.44$ & 0.67 \\
Creatinine $(\mathrm{mg} / \mathrm{dL})$ & $0.76 \pm 0.36$ & $0.66 \pm 0.20$ & 0.30 \\
\hline
\end{tabular}

Data are expressed as the mean $\pm \mathrm{SD}$. $\mathrm{Hb}$ : hemoglobin, $\mathrm{Na}$ : sodium, $\mathrm{K}$ : potassium.

Table 3. Patients' intraoperative factors

\begin{tabular}{|c|c|c|c|}
\hline Variable & $\begin{array}{l}\text { Restrictive } \\
\text { transfusion therapy } \\
(n=72)\end{array}$ & $\begin{array}{c}\text { Conventional } \\
\text { transfusion therapy } \\
(n=72)\end{array}$ & $\mathrm{p}$ value \\
\hline Anesthetic time (min) & $165.7 \pm 45.4$ & $167.5 \pm 52.7$ & 0.14 \\
\hline $\mathrm{EBL}(\mathrm{mL})$ & $651.4 \pm 388.0$ & $645.8 \pm 393.6$ & 0.97 \\
\hline $\begin{array}{l}\text { Total fluid during } \\
\text { anesthesia }(\mathrm{mL})\end{array}$ & $2,249.3 \pm 1,329.2$ & $2,185.4 \pm 1,190.7$ & 0.37 \\
\hline pRBC (pint) & $0.6 \pm 1.7$ & $1.2 \pm 1.6$ & $0.04^{*}$ \\
\hline
\end{tabular}

Data are expressed as mean \pm SD. EBL: estimated blood loss, pRBC: packed red blood cells. ${ }^{*} \mathrm{p}>0.05$.

ferences in blood pressure variation during surgery $(\mathrm{p}>0.05)$, the use of vasopressors ( $p>0.05)$, and the total dose of postoperative pethidine $(p>0.05)$ between the two groups. There was a significant difference in the total amount of $\mathrm{RBC}$ transfusion in the two patient groups $(\mathrm{p}=0.04)$, but the other factors showed no statistical differences. The mean serum $\mathrm{Hb}$ concentrations after surgery were $9.11 \pm 0.73$ and $11.46 \pm 0.99 \mathrm{~g} / \mathrm{dL}$ in the restrictive transfusion strategy and the conventional transfusion strategy groups, respectively $(\mathrm{p}<0.001)$. The mean serum $\mathrm{Cr}$ levels 48 hours after surgery were $0.76 \pm 0.36$ and $0.66 \pm 0.20 \mathrm{mg} / \mathrm{dL}$ in the restrictive transfusion strategy and the conventional transfusion strategy groups, respectively $(\mathrm{p}=0.30)$. AKI occurred in three patients (4.5\%) in the restrictive transfusion strategy group and in two patients (2.8\%) in the conventional transfusion strategy group ( $\mathrm{p}=0.99)$. All patients with AKI had stage I injuries. In addition, the total number of patients receiving a transfusion was 78 and the number of patients who did not receive a transfusion was 66 . There was no difference in the incidence of AKI whether patients received a transfusion or $\operatorname{not}(\mathrm{p}=0.11)$.

\section{DISCUSSION}

This study showed that there were no differences in the incidence of AKI with the use of a different transfusion therapy when proper fluids were maintained during surgery. We used the conventional transfusion method and restrictive transfusion method while monitoring stroke volume variation, but there was no difference in the incidence of AKI after THRA.

An increase in human life expectancy, along with the advancement of medicine and technology, has resulted in increased rates of femoral neck fracture. THRA is usually performed on older individuals and may produce debilitating or even fatal outcomes [8]. A number of indices, including the Charlson Comorbidity Index, the Barthel Index, and the ASA score can help predict the risk of chronic physical or mental illness and organ failure related to increased morbidity and mortality in patients undergoing THRA $[9,10]$. In THRA patients, perioperative AKI is associated with increased morbidity and mortality, prolonged hospital stays, and poorer outcomes [4,11].

A variety of factors were associated with postoperative AKI after THRA, including hypovolemia due to prolonged dehydration or hemorrhage during the perioperative period. AKI often occurs as a result of renal hypoperfusion and may be exacerbated by certain nephrotoxic medications or pre-existing medical conditions such as vascular disease. Risk factors for development of AKI include male sex, hypertension, diabetes mellitus, and pre-morbid chronic renal disease. Patients suffering from both preoperative and postoperative acute medical complications such as sepsis, acute myocardial infarction, heart failure, pyelonephritis, and pulmonary embolism also have a higher incidence of prerenal AKI. In addition, renal artery occlusions due to embolism or thrombus, which may be associated with drugs such as aminoglycosides, amphotericin B, NSAIDs, proton-pump inhibitors, or radiocontrast agents, are generally thought to cause AKI [12]. These drugs and conditions exacerbate vasoconstriction in the kidneys and further decrease the medullary blood supply. AKI also occurs more frequently in patients taking diuretics, angiotensin-converting enzyme (ACE) inhibitors, or angiotensin II receptor blockers. The long-term use of ACE inhibitors especially causes impairment of the renin-angiotensin system to compensate for the reduction 
of renal perfusion, thereby resulting in renal ischemia [13]. In addition, reduced blood flow in the glomerulus may also lead to increased incidence of adverse drug reactions due to prolongation of the half-life of the drug or the accumulation of its metabolites (e.g., opiates), as well as changes in bioavailability and plasma protein-binding capacity.

Anemia in both chronic and acute conditions is related to an increased risk of injury to major vital organs such as the heart, brain, liver, and kidneys, as well as increased morbidity and mortality. Hence, RBC transfusions are intended to augment the delivery of oxygen in order to avoid the deleterious effects of oxygen deficiency [14]. Improvement of tissue oxygen delivery is supported by existing anemia treatments which include erythropoiesis-stimulating agents, transfusion, and blood substitutes. Although patient blood management strategies are designed to improve patient outcomes, none of the aforementioned interventions have produced clearly demonstrable improvement and, therefore, the routine use of transfusion in surgery or in critically ill patients is supported in current resuscitation protocols. Additionally, concerns about the adequate supply and safety of the blood supply have led to a conservative approach to transfusion which is an important consideration for THRA patients and the surgeons who treat them.

In patients who have experienced acute blood loss during surgery, those with an estimated mean $\mathrm{Hb}$ value of approximately $2.5 \mathrm{~g} / \mathrm{dL}$ often experience fatal outcomes [15]. An individual patient's $\mathrm{Hb}$ threshold for tissue hypoxia and the impact of anemia are multifactorial, highly variable, and patient-specific. This variability led to the development of multiple protocols based on patient circumstances in our clinic. Generally, the lowest acceptable $\mathrm{Hb}$ level is $8.0 \mathrm{~g} / \mathrm{dL}$ [16], but some patients, such as those undergoing cardiac surgery, older patients, or those with severe comorbidities have an increased risk of mortality if they have an $\mathrm{Hb}$ value lower than $10.0 \mathrm{~g} / \mathrm{dL}[17,18]$. Hence, anesthesiologists use different threshold levels for $\mathrm{Hb}$ based on the patient's genetic background, their general condition, whether they have undergone surgery, and their associated comorbidities. The strategy of transfusing according to $\mathrm{Hb}$ level for an overall population requires careful consideration. We attempted to discern objective and reliable guidelines for patients undergoing surgery that could decrease the risk of anemia and conditions which would normally lead to tissue hypoxia, major organ injury, or even death.

Recent transfusion threshold guidelines [1,19] and strategies for RBC treatment suggest that the use of a restrictive transfusion strategy (threshold, $7.0 \mathrm{~g} / \mathrm{dL}$ of $\mathrm{Hb}$; maintenance range of 7.0-9.0 g/dL of $\mathrm{Hb}$ ) is more effective than a liberal transfusion strategy (threshold, $10.0 \mathrm{~g} / \mathrm{dL}$ of $\mathrm{Hb}$; maintenance range, $10.0-12.0 \mathrm{~g} / \mathrm{dL}$ of $\mathrm{Hb}$ ) in critically ill patients with normovolemia. Patients who were treated with a restrictive transfusion strategy showed decreased 30day mortality rates as well as reduced rates of major organ dysfunction and cardiac complications [1,19]. Additionally, the patients who were treated with a restrictive transfusion strategy only required $54 \%$ of the average number of RBC transfusion units. Therefore, these reports recommended a restrictive transfusion strategy for surgical or critically ill patients with the exception of patients with unstable angina and acute myocardial infarction. Preoperative anemia was shown to be an independent predictor of AKI [18,20]. Reduced oxygen delivery or harmful effects of transfusions may induce postoperative AKI. During the perioperative period, maintaining a low $\mathrm{Hb}$ level increases the likelihood of an increase in urea, hypovolemia, and the presence of oliguria, which can lead to postoperative AKI.

Our study found that perioperative restrictive transfusion or conventional transfusion in patients undergoing elective THRA due to hip fracture is not related to AKI. Low $\mathrm{Hb}$ (lower than $10.0 \mathrm{~g} / \mathrm{dL}$ of $\mathrm{Hb}$ ) with proper volume status does not affect the incidence of AKI. Patients with THRA should be able to receive adequate transfusion with proper fluid maintenance during surgery without worrying about AKI because there were no differences in the incidence of AKI with different transfusion therapies. Anesthesiologists need to consider many other factors of patient condition when applying any transfusion strategy.

\section{CONFLICT OF INTEREST}

No potential conflict of interest relevant to this article was reported.

\section{REFERENCES}

1. Carson JL, Carless PA, Hebert PC. Transfusion thresholds and other strategies for guiding allogeneic red blood cell transfu- 
sion. Cochrane Database Syst Rev 2012;(4):CD002042.

2. Napolitano LM, Corwin HL. Efficacy of red blood cell transfusion in the critically ill. Crit Care Clin 2004;20:255-68.

3. Hébert PC, Yetisir E, Martin C, Blajchman MA, Wells G, Marshall $\mathrm{J}$, et al. Is a low transfusion threshold safe in critically ill patients with cardiovascular diseases? Crit Care Med 2001;29:227-34

4. Bennet SJ, Berry OM, Goddard J, Keating JF. Acute renal dysfunction following hip fracture. Injury 2010;41:335-8.

5. Jameson SS, Khan SK, Baker P, James P, Gray A, Reed $\mathrm{MR}$, et al. A national analysis of complications following hemiarthroplasty for hip fracture in older patients. QJM 2012;105:455-60.

6. Mehta RL, Kellum JA, Shah SV, Molitoris BA, Ronco C, Warnock DG, et al. Acute Kidney Injury Network: report of an initiative to improve outcomes in acute kidney injury. Crit Care 2007;11:R31.

7. Faul F, Erdfelder E, Lang AG, Buchner A. G*Power 3: a flexible statistical power analysis program for the social, behavioral, and biomedical sciences. Behav Res Methods 2007;39:175-91.

8. Castronuovo E, Pezzotti P, Franzo A, Di Lallo D, Guasticchi G. Early and late mortality in elderly patients after hip fracture: a cohort study using administrative health databases in the Lazio region, Italy. BMC Geriatr 2011;11:37.

9. Heller DA, Ahern FM, Pringle KE, Brown TV. Among older adults, the responsiveness of self-rated health to changes in Charlson comorbidity was moderated by age and baseline comorbidity. J Clin Epidemiol 2009;62:177-87.

10. Bjorgul K, Novicoff WM, Saleh KJ. American Society of Anesthesiologist Physical Status score may be used as a comorbidity index in hip fracture surgery. J Arthroplasty 2010;25(6 Suppl):134-7.

11. Jafari SM, Huang R, Joshi A, Parvizi J, Hozack WJ. Renal impairment following total joint arthroplasty: who is at risk? J
Arthroplasty 2010;25(6 Suppl):49-53, 53.e1-2.

12. Schrier RW, Wang W, Poole B, Mitra A. Acute renal failure: definitions, diagnosis, pathogenesis, and therapy. J Clin Invest 2004;114:5-14.

13. Cittanova ML, Zubicki A, Savu C, Montalvan C, Nefaa N, Zaier $\mathrm{K}$, et al. The chronic inhibition of angiotensin-converting enzyme impairs postoperative renal function. Anesth Analg 2001;93:1111-5.

14. Russell JA, Phang PT. The oxygen delivery/consumption controversy. Approaches to management of the critically ill. Am J Respir Crit Care Med 1994;149:533-7.

15. Shander A, Javidroozi M, Ozawa S, Hare GM. What is really dangerous: anaemia or transfusion? Br J Anaesth 2011;107 Suppl 1:i41-59.

16. Rao SV, Jollis JG, Harrington RA, Granger CB, Newby LK, Armstrong PW, et al. Relationship of blood transfusion and clinical outcomes in patients with acute coronary syndromes. JAMA 2004;292:1555-62.

17. Karkouti K, Wijeysundera DN, Beattie WS; Reducing Bleeding in Cardiac Surgery (RBC) Investigators. Risk associated with preoperative anemia in cardiac surgery: a multicenter cohort study. Circulation 2008;117:478-84.

18. Kulier A, Levin J, Moser R, Rumpold-Seitlinger G, Tudor IC, Snyder-Ramos SA, et al. Impact of preoperative anemia on outcome in patients undergoing coronary artery bypass graft surgery. Circulation 2007;116:471-9.

19. Hébert PC, Wells G, Blajchman MA, Marshall J, Martin C, Pagliarello G, et al. A multicenter, randomized, controlled clinical trial of transfusion requirements in critical care. Transfusion Requirements in Critical Care Investigators, Canadian Critical Care Trials Group. N Engl J Med 1999;340:409-17.

20. Zindrou D, Taylor KM, Bagger JP. Preoperative haemoglobin concentration and mortality rate after coronary artery bypass surgery. Lancet 2002;359:1747-8. 